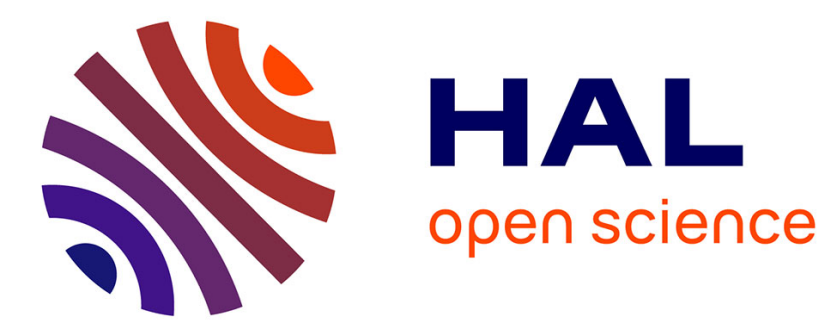

\title{
A predictive surface profile model for turning based on spectral analysis \\ Jean-Philippe Costes
}

\section{To cite this version:}

Jean-Philippe Costes. A predictive surface profile model for turning based on spectral analysis. Journal of Materials Processing Technology, 2013, 213 (Issue 1), pp94-100. 10.1016/j.jmatprotec.2012.08.009 . hal-01087817

\section{HAL Id: hal-01087817 https://hal.science/hal-01087817}

Submitted on 26 Nov 2014

HAL is a multi-disciplinary open access archive for the deposit and dissemination of scientific research documents, whether they are published or not. The documents may come from teaching and research institutions in France or abroad, or from public or private research centers.
L'archive ouverte pluridisciplinaire HAL, est destinée au dépôt et à la diffusion de documents scientifiques de niveau recherche, publiés ou non, émanant des établissements d'enseignement et de recherche français ou étrangers, des laboratoires publics ou privés. 


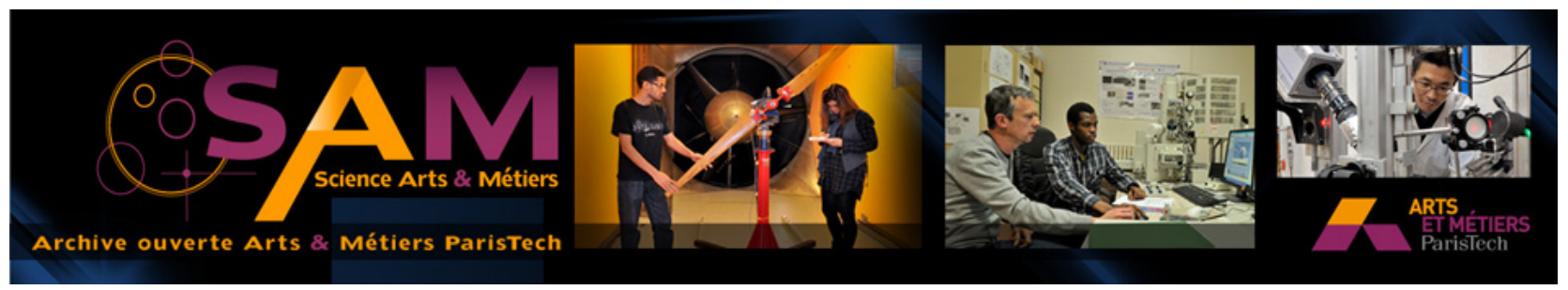

Science Arts \& Métiers (SAM)

is an open access repository that collects the work of Arts et Métiers ParisTech researchers and makes it freely available over the web where possible.

This is an author-deposited version published in: http://sam.ensam.eu Handle ID: .http://hdl.handle.net/10985/8993

\section{To cite this version :}

Jean-Philippe COSTES - A predictive surface profile model for turning based on spectral analysis - Journal of Materials Processing Technology - Vol. 213, nIssue 1, p.pp94-100 - 2013 


\title{
A predictive surface profile model for turning based on spectral analysis
}

\author{
Jean-Philippe Costes* \\ Arts et Metiers ParisTech, LABOMAP, rue porte de Paris, 71250 Cluny, France
}

\begin{abstract}
A B S T R A C T
This article presents a predictive approach of surface topography based on the FFT analysis of surface profiles. From a set of experimental machining tests, the parameters investigated are: feed per revolution, insert nose radius, depth of cut and cutting speed. The first step of the analysis consists of normalizing the measured profiles with the feed per revolution. This results in normalized profiles with a feed per revolution and a signal period equal to 1 . The effect of each cutting parameter on the surface profile is expressed as a spectrum with respect to the period length. These effects are quantified and can be sorted in descending order of importance as feed per revolution, insert nose radius, depth of cut and cutting speed. The second part of the paper presents a modeling of the surface profile using the parameters effects and one interaction. The proposed model gives the spectrum of the profile to be predicted. The inverse Fourier transform applied to the spectrum yields the expected surface profile. Measured and simulated profiles are compared for two cutting conditions and results correlate well.
\end{abstract}

\section{Introduction}

Guaranteeing the required quality of manufactured surfaces is of great interest to industrialists. The topography of the generated surface plays a major role in product quality and in tribological properties such as wear, friction and lubricant retentivity. Consequently, surface profile prediction could be helpful for manufacturers in order to set the appropriate cutting parameters to achieve a desired surface profile. In 2003, Benardos and Vosniakos (2003) presented a review of various studies with regard to surface roughness prediction. The authors classified the different approaches to turning and milling encountered in the literature into four categories: machining theory, experimental investigation, designed experiments and Artificial Intelligence (AI).

Numerous studies focus on the prediction of surface roughness parameters such as $R_{a}$ and $R_{t}$ by experimental investigation and designed experiments. Cakir et al. (2009) investigated the effect of cutting parameters and insert coating material on $R_{a}$ roughness parameter. Wang and Chang (2004) used Response Surface Methodology (RSM) to build experimental $R_{a}$ models in slot milling for dry-cutting and coolant conditions. Although these methodologies give good results, the conclusions arrived at have little or no general application. Moreover, the above-mentioned roughness parameters are not appropriate to depict correctly the tribological properties of the generated surfaces.

\footnotetext{
* Tel.: +33 3855953 58; fax: +33 385595370 .

E-mail address: jean-philippe.costes@ensam.eu
}

Studies related to the influence of cutting parameters on roughness are abundant: Selvam and Balakrishnan (1977) studied the effects of cutting speed, feed rate, depth of cut and rake angle on measured $R_{a}$ and $R_{t}$. Regarding the profile, the authors used auto-correlation functions to investigate their randomness or periodicity. No surface profile predictive model was established but interesting results were brought to light: the measured surface profile is more random at low cutting speed and low feed rates. Selvam explains these results by built-up edge growth and fracture, and the amount of side-flow and tearing that occur proportionally more frequently at low cutting speeds and low feed rates. Grzesik (1996) established a predictive model for $R_{a}$ and $R_{z}$ based on a mechanistic approach by considering the minimum un-deformed chip thickness. Some authors developed surface roughness prediction models based on neural network methodology. Most of these studies also focus on the prediction of the roughness criteria $R_{a}, R_{t}$. Karayel (2009) built a neural network model to predict $R_{a}, R_{z}$ and $R_{\max }$ in turning: 120 preliminary machining tests were required in order to train the model. Asilturk and Çunkaş (2011) proposed a similar way for $R_{a}$ prediction in turning using neural network and multiple regression methods.

The above mentioned neural network studies do not investigate the prediction of surface topography and usually require a large number of training tests. Although these models are of great interest particularly in the industrial context, the roughness criteria such as $R_{a}$ or $R_{t}$ are not as useful as the roughness profile from a tribological point of view.

Based on neural network method, Lu et al. (2008) developed a predictive model of surface profile in turning. Prediction and measured profiles for the tested machining conditions are found in 
good correlation; nevertheless, the authors outline the dependence between the training parameters and the conditions to be tested. The authors show simulated versus measured profile results for various (depth of cut, cutting speed, feed rate) conditions with cutting parameters exactly or very close to those of the cutting parameter of the training data set. Consequently, the correlation of the neural network model for random cutting parameter values in the investigated range cannot be accurately established.

El-Sonbaty et al. (2008) used a fractal geometry model and a neural network identification to simulate the surface profile in milling. 36 machined surfaces were measured each at 6 positions tests leading to 216 profiles measurements in order to train the model. As mentioned by the authors, the conclusion is that the simulated and measured profiles are not identical. Nevertheless, the same probability distribution function of the signals is observed. The authors explained the differences between the actual and predicted profiles by the randomness of the surface roughness profile measurement process.

Consequently, although many authors investigated the roughness criteria as $R_{a}$ or $R_{t}$ a very few predictive models of the surface profiles were developed. Moreover, the neural network methods usually require numerous measurements in order to be trained. Also, the neural network model is usually considered as a blackbox that gives a result for a given set of data but this result may be difficult to interpret further.

Regarding the surface profile prediction, some authors have proposed numerical models based on the relative kinematics of the tool edge and the material part. Quinsat et al. (2008) investigated the pattern obtained on the machined surface in the case of ball end mill. Considering the tool shape and its trajectory, geometrical interactions with the material yield the topography of the generated surface. In these approaches, cutting phenomena at the tool edge scale as well as mechanical and dynamics effects are usually neglected in the computation of the profile. Arizmendi et al. (2009) built models where the tool and work piece system dynamics are considered for side milling process. Here, the dynamic displacements occurring in the tool/work piece system are measured while the machining operation is processed. The measured dynamic are then used in addition to the exact kinematics of the tool in order to compute the actual envelope swept by the tool edge. Costes and Moreau (2011) developed a similar approach in end milling. Surface profile prediction in turning was also investigated using the same methodology by Lin and Chang (1998). The principle of these methods is that for a given machining condition the roughness profile is calculated from the tool displacements measured during the machining operation. Although these dynamic methods show good correlation between predicted and measured profiles, these methods are not predictive as usually understood since the machining test for a given condition has yet to be conducted. This is the main drawback of these methods.

Numerous articles cover surface characterization: Wu (2000) applied an FFT analysis for three-dimensional surfaces. Josso et al. (2001) investigated the modeling of surface topography with wavelet transform. Grzesik and Brol (2009) characterized machined surfaces using wavelet together with fractal functions. The main objective followed by the authors is to identify ways of texture characterization for manufactured surfaces. Surface topography prediction is not investigated by these authors.

As explained above, if many authors have carried out interesting results regarding the prediction of roughness parameters such as $R_{a}$ or $R_{t}$, a very few have investigated the roughness profile prediction. In the present paper, a model of surface topography prediction by means of FFT operations is presented. In order to enable comparisons and the development of a surface profile model, the scanned axis of the surface profiles is normalized with respect to the feedrate. The model is based on an experimental design table where the

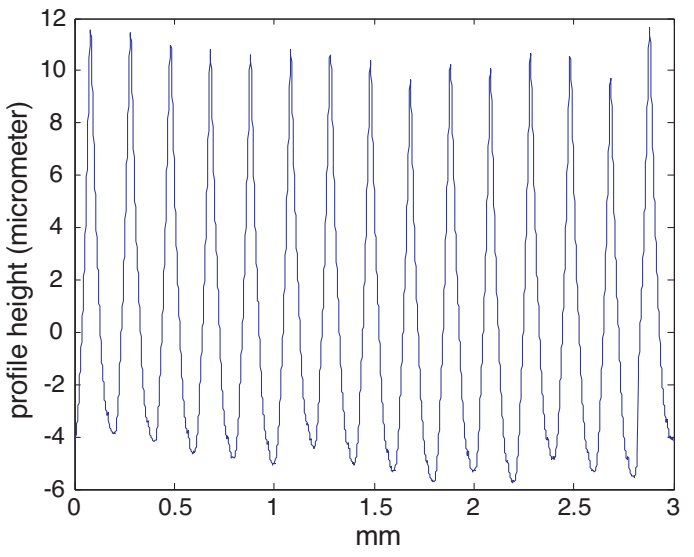

Fig. 1. Surface profile for test no. 2 .

parameter effects and interaction are investigated and evaluated in terms of spectra.

\section{Surface profile model}

An innovative method for surface profile prediction is presented here. It is based on 8 preliminary turning machining tests for a given set of cutting conditions. The approach is based on an experimental design and the mathematical processing of the measured profiles using FFT. The parameters investigated in the preliminary tests are: feed per revolution $f$, insert nose radius $R_{\varepsilon}$, depth of cut $a_{p}$ and cutting speed $V_{c}$. The surface profiles of the preliminary machining tests are measured with a mechanical profilometer. Each of the obtained profiles shows a quasi-periodic signal with a period equal to the feed per revolution.

The effects of the four above-mentioned parameters as well as the interaction between $f$ and $R_{\varepsilon}$ are the elements under investigation. The profile to be predicted will be written following the experimental design modeling:

$Y_{\text {Prediction }}=\bar{Y}+$ Effect $_{R_{\varepsilon}}+$ Effect $_{f}+$ Effect $_{a_{p}}+$ Effect $_{V_{c}}+$ Inter $_{f_{R_{\varepsilon}}}$

where $Y_{\text {Prediction }}$ is the expected surface profile for a given set of cutting conditions $\left(R_{\varepsilon}, f, a_{p}, V_{c}\right)$. More precisely, $Y_{\text {Prediction }}$ is the distribution of heights for the expected profile. $\bar{Y}$ is the average profile obtained for the 8 preliminary tests. Effect $_{R_{\varepsilon}}$, Effect $_{f}$, Effect $_{a_{p}}$ and Effect $_{V_{c}}$ are the effects of the four cutting parameters on the surface profile. Inter $f_{\mathcal{L} R_{\varepsilon}}$ is the interaction between the feed rate and the insert radius.

Each preliminary machining test yields a surface profile $Y_{i}(x)$ with $i \in(1 \ldots 8)$ where $Y$ is the height of the measured point at position $x$. It is assumed that the period of the $i \in(1 \ldots 8)$ measured profiles is equal to $f_{i}$, the feed per revolution. This assumption can be easily checked for all the 8 profiles. Eq. (1) is first expressed in a spectral form as:

$$
\begin{aligned}
F\left\{Y_{\text {Prediction }}\right\}= & \overline{F\{Y\}}+F\left\{\text { Effect }_{R_{\varepsilon}}\right\}+F\left\{\text { Effect }_{f}\right\}+F\left\{\text { Effect }_{a_{p}}\right\} \\
& +F\left\{\text { Effect }_{V_{c}}\right\}+F\left\{\text { Inter }_{f_{R_{\varepsilon}}}\right\}
\end{aligned}
$$

where each component of Eq. (2) is a spectrum, i.e. a complex function of frequency $\left(\mathrm{mm}^{-1}\right)$ or period $(\mathrm{mm})$.

Before identifying the model, the first stage consists of normalizing the 8 profiles $Y_{i}(x)$ of the preliminary machining tests with the feed per revolution $f_{i}$. This is performed by dividing the scanning $x$-axis of profile no. $i$ by the value of the feed per revolution $f_{i}$. It results in 8 normalized profiles $Y_{\mathrm{Norm}_{i}}(x)$ with a feed per revolution and a signal period equal to 1 . Figs. 1 and 2 illustrate respectively 


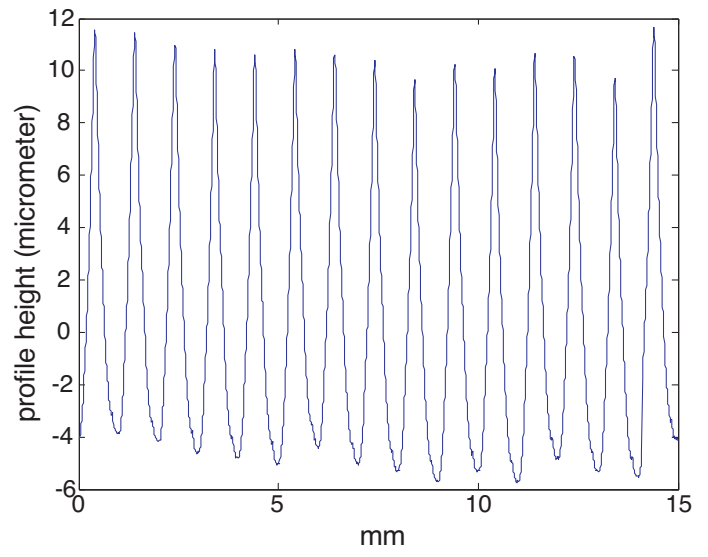

Fig. 2. Normalized surface profile for test no. 2 .

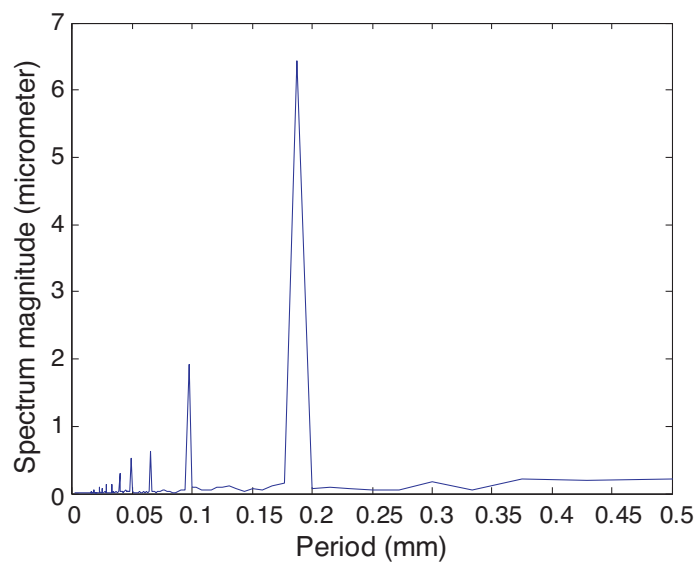

Fig. 3. Spectrum of $\mathcal{F}\left\{Y_{2}\right\}$.

the initial measured profile and the normalized profile for the same machined surface.

The second stage of the process consists of a FFT of the normalized profile $Y_{\mathrm{Norm}_{i}}(x)$ for each test $i, i \in(1 \ldots 8) . \mathcal{F}\left\{Y_{\mathrm{Norm}_{i}}\right\}(l)$ is the FFT complex value of $Y_{\mathrm{Norm}_{i}}(x)$ at a period $l$ in $\mathrm{mm}$. The following figures display the FFT of the measured and normalized profiles for test no. 2. The graphs show the modulus of the two FFT spectra with respect to the signal period in $\mathrm{mm}$. Although FFT $x$-axis usually shows frequency values in $\mathrm{mm}^{-1}$, period values in $\mathrm{mm}$ have been displayed here since it is easier to interpret (Figs. 3 and 4).

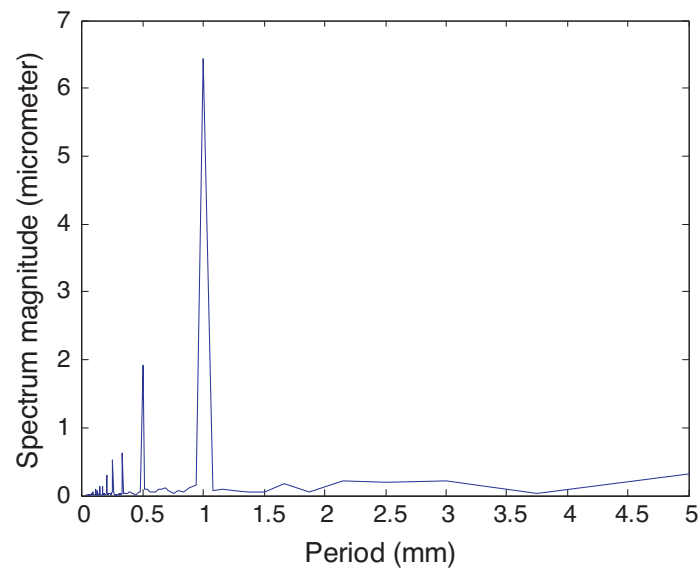

Fig. 4. Spectrum of $\mathcal{F}\left\{Y_{\mathrm{Norm}_{2}}\right\}$.
Table 1

Parameters and levels.

\begin{tabular}{lllll}
\hline Test no. & $R_{\varepsilon}(\mathrm{mm})$ & $V_{c}(\mathrm{~m} / \mathrm{min})$ & $f(\mathrm{~mm} / \mathrm{rev})$ & $a_{p}(\mathrm{~mm})$ \\
\hline 1 & 0.4 & 100 & 0.07 & 0.1 \\
2 & 0.4 & 100 & 0.2 & 0.4 \\
3 & 0.4 & 400 & 0.07 & 0.4 \\
4 & 0.4 & 400 & 0.2 & 0.1 \\
5 & 0.8 & 100 & 0.07 & 0.4 \\
6 & 0.8 & 100 & 0.2 & 0.1 \\
7 & 0.8 & 400 & 0.07 & 0.1 \\
8 & 0.8 & 400 & 0.2 & 0.4 \\
\hline
\end{tabular}

The FFT operation on each of the 8 normalized profiles generates 8 spectra with a maximum magnitude centered on a period equal to $1 \mathrm{~mm}$. This property will enable the calculation of each of the terms of Eq. (2). This will be described in the following section.

\section{Identification of the model}

\subsection{Experimental tests}

A set of 8 cutting conditions are applied in turning. The cutting conditions for test no. $i$ will be written as: $f_{i}, V_{c_{i}}, a_{p_{i}}, R_{\varepsilon_{i}}$ and are given in Table 1 . The Taguchi table $\mathrm{L} 8\left(2^{7}\right)$ is suitable for model identification (Fig. 5).

Each test consists of a longitudinal turning operation using two VCGT 1604 carbide tools with $R_{\varepsilon}=0.4 \mathrm{~mm}$ and $0.8 \mathrm{~mm}$. The work piece is a $304 \mathrm{~L}$ stainless steel that is divided into eight $10 \mathrm{~mm}$ width surfaces separated by grooves.

Surfaces profiles are measured using a Somicronic Surfascan SM3 mechanical profilometer and a stylus with a radius of $2 \mu \mathrm{m}$, angle $90^{\circ}$. The vertical resolution of the measured profiles is $0.03 \mu \mathrm{m}$ with a scanning period of 1 point per $\mu \mathrm{m}$ for the longitudinal axis. $f_{s}$ will refer to the scanning frequency which here is $1000 \mathrm{pts} \mathrm{mm}^{-1}$. Since the measurement length of each profile is $3 \mathrm{~mm}$, the profile consists of 3000 points.

The profile spectrum $\overline{\mathcal{F}\{Y\}}$ for the 8 experimental tests is obtained as follows: for each period $l$ value, the average of the 8 Fourier components $\mathcal{F}\left\{Y_{\mathrm{Norm}_{i}}\right\}(\ell), i \in(1 \ldots 8)$ is calculated using:

$\overline{\mathcal{F}\{Y\}}(\ell)=\frac{1}{8} \sum_{i=1}^{8} \mathcal{F}\left\{Y_{\mathrm{Norm}_{i}}\right\}(\ell)$

Fig. 6 shows the average spectrum $\overline{\mathcal{F}\{Y\}}$ and two profile spectra among the 8 measured.

According to the experimental design definition, the effect of parameter $P$ at level $j$ can be introduced as:

$$
\begin{aligned}
E_{p_{j}}= & \text { (Average of tests with } P \text { at level } j) \\
& - \text { Average of all tests }
\end{aligned}
$$

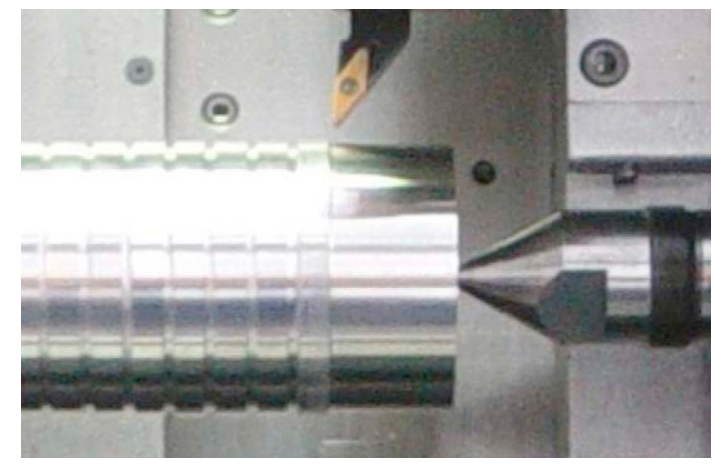

Fig. 5. Work-piece and tool before the turning operations. 


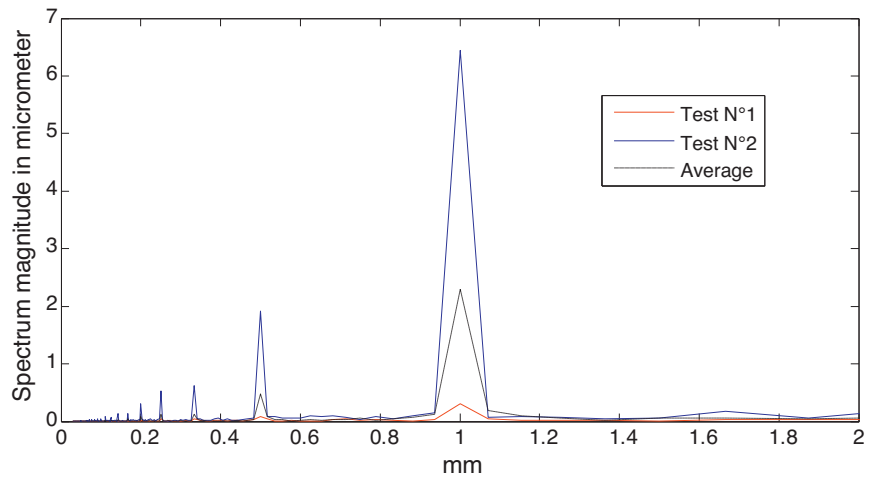

Fig. 6. Spectra of $\mathcal{F}\left\{Y_{\mathrm{Norm}_{1}}\right\}, \mathcal{F}\left\{Y_{\mathrm{Norm}_{8}}\right\}$ and $\overline{\mathcal{F}\{Y\}}$. Only two measured profile spectra are plotted with the average spectrum for reading convenience.

The effect of the parameter $P_{j}$ can also be written in its spectral form as:

$\mathcal{F}\left\{E_{P_{j}}\right\}={\overline{\mathcal{F}\left\{Y_{\text {Norm }_{i}}\right.}}_{i / P_{i}=P_{j}}-\overline{\mathcal{F}\{Y\}}$

For the effect of cutting speed $V_{c}$ at level 1, Eq. (4) yields:

$\mathcal{F}\left\{E_{V c_{1}}\right\}=\overline{\mathcal{F}\left\{Y_{\text {Norm }_{i}}\right.}{ }_{i / V_{c_{i}}=V_{c_{1}}}-\overline{\mathcal{F}\{Y\}}$

where $\left.\overline{\mathcal{F}\left\{Y_{\text {Norm }_{i}}\right.}\right\}_{i / V_{c_{i}}=V_{c_{1}}}$ is the average profile spectrum for $V_{c}$ at

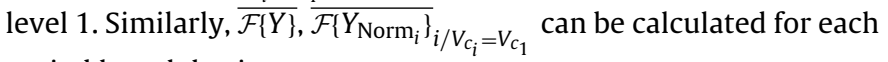
period length 1 using:

${\overline{\mathcal{F}\left\{Y_{\mathrm{Norm}_{i}}\right.}}_{i / V_{c_{i}}=V_{c_{1}}}(\ell)=\frac{1}{4} \sum_{i=1,2,5,6} \mathcal{F}\left\{Y_{\mathrm{Norm}_{i}}\right\}(\ell)$

According to the experimental design theory, it can be noticed that the effect matrix of a parameter $P$ with $n$ levels satisfies:

$\sum_{i=1}^{n} E_{P_{i}}=0$

In the case of a 2-level parameter $P$, this results in:

$\mathcal{F}\left\{E_{P_{1}}\right\}=-\mathcal{F}\left\{E_{P_{2}}\right\}$

Consequently, the effects of cutting speed, feed rate, depth of cut and insert radius can be expressed in the following form:

$\mathcal{F}\left\{E_{V_{c}}\right\}=\left(\begin{array}{c}\mathcal{F}\left\{E_{V_{c_{1}}}\right\} \\ -\mathcal{F}\left\{E_{V_{c_{1}}}\right\}\end{array}\right)$

$\mathcal{F}\left\{E_{f}\right\}=\left(\begin{array}{c}\mathcal{F}\left\{E_{f_{1}}\right\} \\ -\mathcal{F}\left\{E_{f_{1}}\right\}\end{array}\right)$

$\mathcal{F}\left\{E_{a_{p}}\right\}=\left(\begin{array}{c}\mathcal{F}\left\{E_{a_{p 1}}\right\} \\ -\mathcal{F}\left\{E_{a_{p 1}}\right\}\end{array}\right)$

$\mathcal{F}\left\{E_{R_{\varepsilon}}\right\}=\left(\begin{array}{c}\mathcal{F}\left\{E_{R_{\varepsilon 1}}\right\} \\ -\mathcal{F}\left\{E_{R_{\varepsilon 1}}\right\}\end{array}\right)$

For each row of the effect matrix, the columns give the Fourier components with respect to the period length. Similarly, the interaction between $f$ and $R_{\varepsilon}$ is given by:

$I_{f R_{\varepsilon}}=\left(\begin{array}{ll}I_{f_{1} R_{\varepsilon 1}} & I_{f_{1} R_{\varepsilon 2}} \\ I_{f_{2} R_{\varepsilon 1}} & I_{f_{2} R_{\varepsilon 2}}\end{array}\right)$

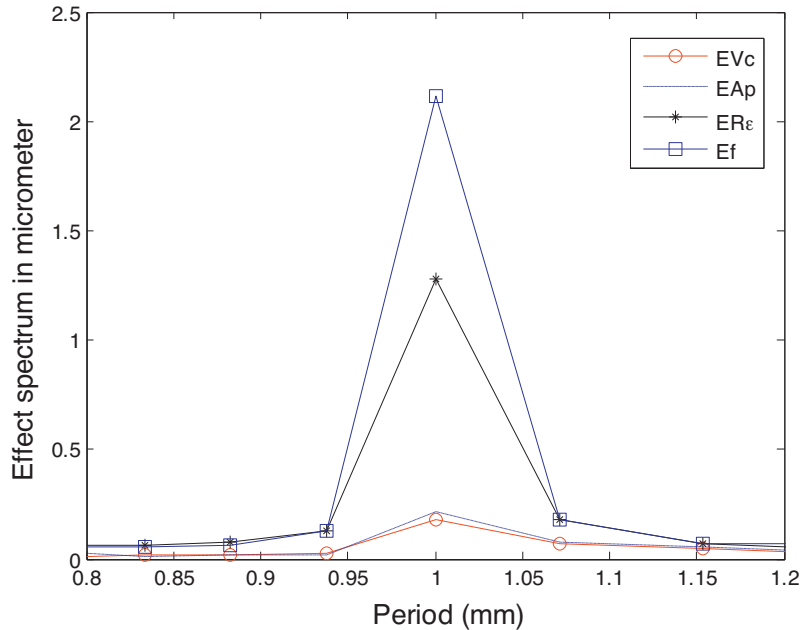

Fig. 7. Effect spectra (modulus) for $a_{p}, V_{c}, f$ and $R_{\varepsilon}$. The $x$-axis is magnified and centered on the $1 \mathrm{~mm}$ period value.

where $I_{f_{i} R_{\varepsilon_{j}}}$ is the interaction spectrum for $f$ at level $i$ and $R_{\varepsilon}$ at level $j$. Following the definition proposed by the experimental design theory, $I_{f_{i} R_{\varepsilon}}$ will be written as:

$\mathcal{F}\left\{I_{f_{i} R_{\varepsilon_{j}}}\right\}=\mathcal{F}\left\{Y_{\text {Norm }_{i j}}\right\}_{\left.\left\{i / f=f_{i}\right\} \cap j / R_{\varepsilon}=R_{\varepsilon_{j}}\right\}}-\mathcal{F}\{Y\}-\mathcal{F}\left\{E_{f_{i}}\right\}-\mathcal{F}\left\{E_{R_{\varepsilon_{j}}}\right\}$

\subsection{Model results}

Fig. 7 displays the effect spectra for $a_{p}, f, V_{c}$ and $R_{\varepsilon}$ calculated at level 1 . For the $1 \mathrm{~mm}$ value, i.e. the normalized feed per revolution, it is quite visible that the magnitude of these effects can be sorted in descending order of importance as $f, R_{\varepsilon}, a_{p}$ and $V_{c}$.

Figs. 8(a-d) and $9(\mathrm{a}-\mathrm{d})$ show the effects for the 4 parameters at levels 1 and 2. It is not surprising that the most significant effects are detected for the feed rate and the nose radius. Variations in cutting speed and depth of cut have little effect on spectrum profile amplitude. In Fig. 9(a-d), the trend observed for the period of the normalized feed rate and for the 4 parameters yields the following well-known result: surface profile is improved when a larger nose radius or a lower feed rate is used. When the depth of cut and the cutting speed are set to the highest values, the surface profiles improve. However, these effects appear to be very narrow and it cannot be definitely concluded from the present machining tests whether these effects are significant or not. The graph of the interaction between the feed rate and the insert nose radius (Fig. 9e), indicates that the effect of one parameter variation depends on the value set for the second. The maximum amplitude is reached for $f=0.2 \mathrm{~mm}$. For this feed rate value, a change in the nose radius from $0.4 \mathrm{~mm}$ to $0.8 \mathrm{~mm}$ gives rise to a large effect on spectrum amplitude, which consists of a decrease in the profile spectrum amplitude. When a $0.07 \mathrm{~mm}$ feed rate value is applied, the same change applied to the nose radius has little effect on the profile.

\section{Simulation of profiles and experimental validation}

Using the profile modeling presented above, 2 cutting condition tests are simulated with values for $f, a_{p}, V_{c}, f$ and $R_{\varepsilon}$ as displayed in Table 2.

For each simulated condition and each cutting parameter, the spectrum effect is calculated with the level value given in the chart. The $f / R_{\varepsilon}$ interaction spectrum is also calculated. Following Eq. (2), the average spectrum, the parameter effect spectra and the $f / R_{\varepsilon}$ interaction spectrum are summed and the result generates the spectrum of the simulated profile. This simulated spectrum 
(a)

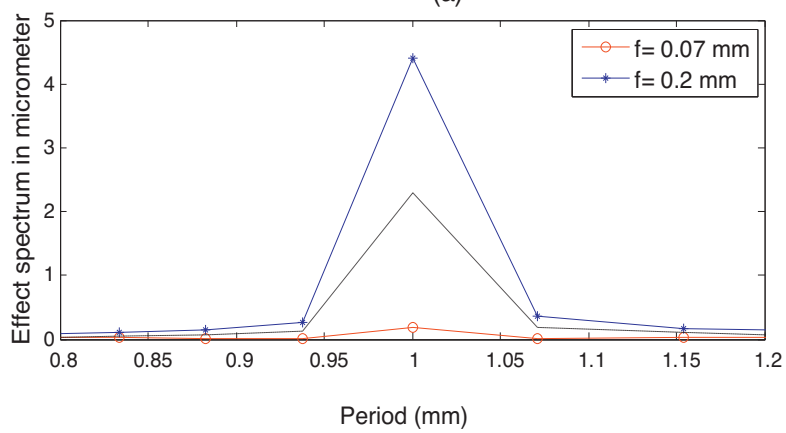

(c)

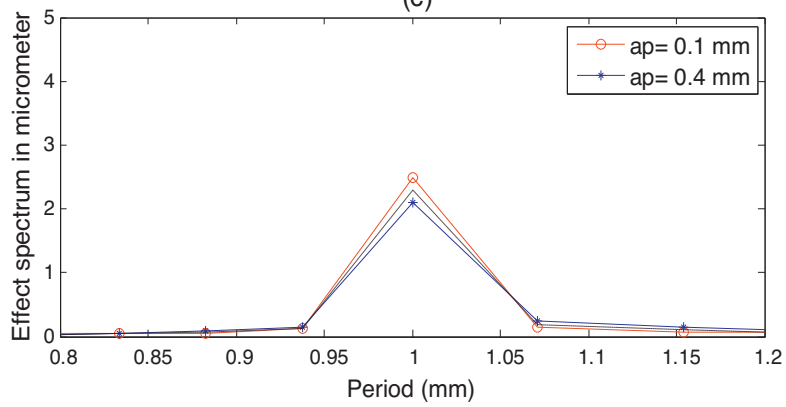

(b)

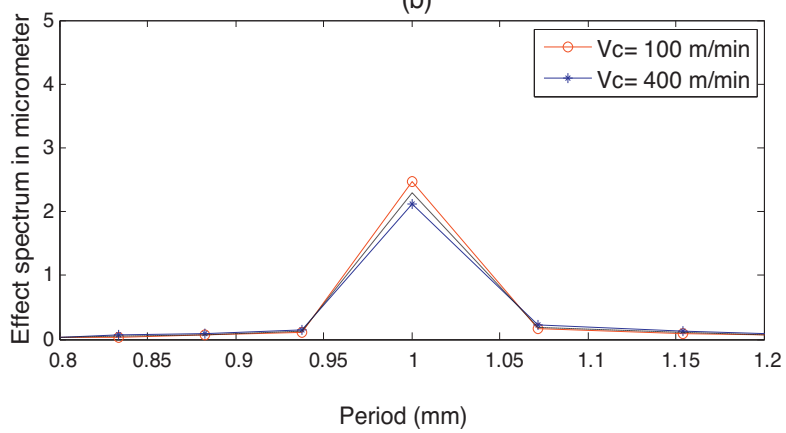

(d)

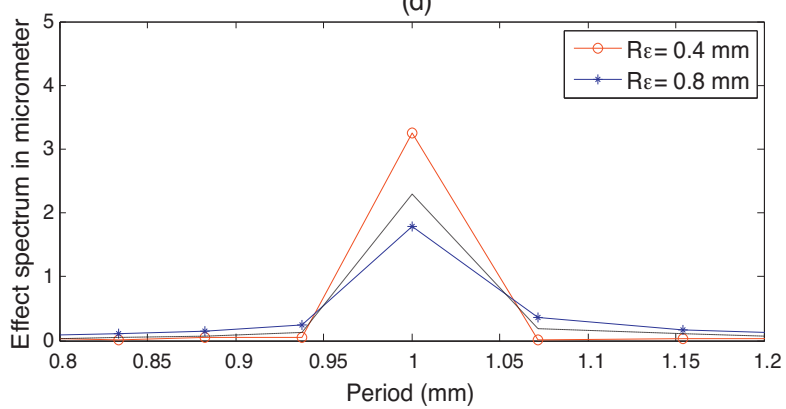

Fig. 8. (a-d) Effect spectra (modulus) for $a_{p}, V_{c}, f$ and $R_{\varepsilon}$ and average spectrum (black line).

(a)
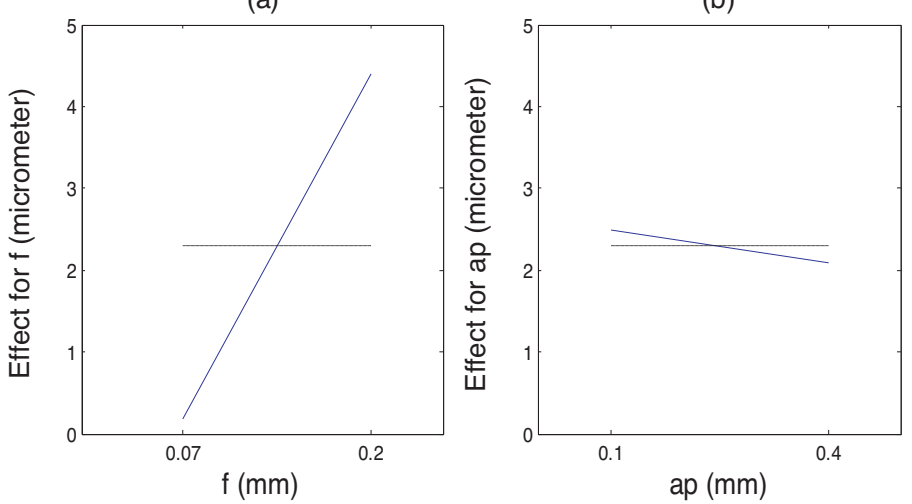

(c)

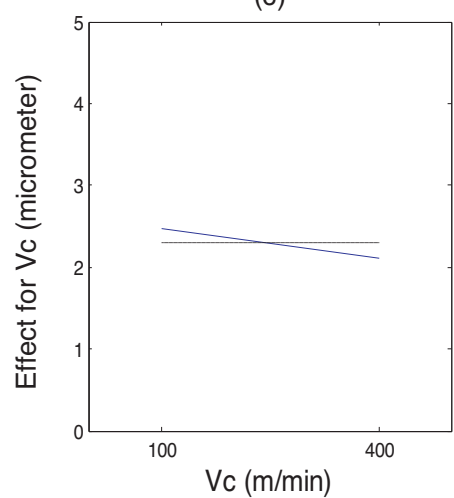

(e)

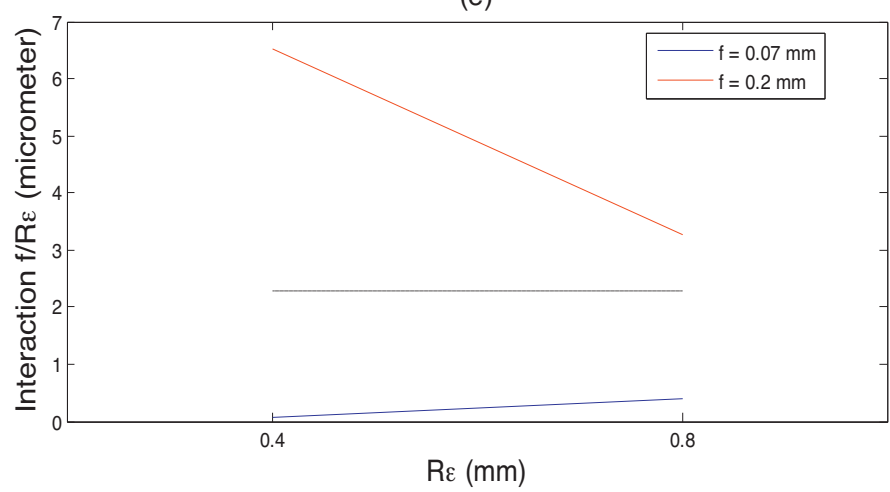

(d)

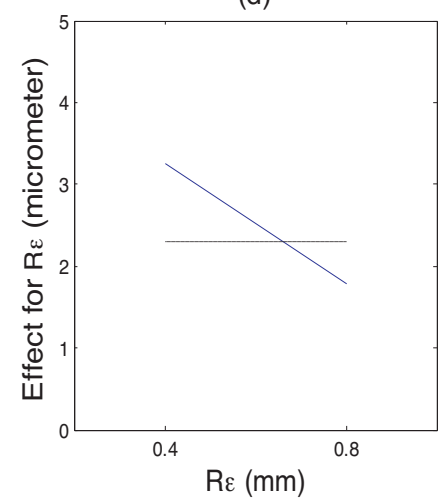

Fig. 9.

Table 2

Cutting conditions (a) and (b) for experimental validation.

\begin{tabular}{lcc}
\hline & $(\mathrm{a})$ & $(\mathrm{b})$ \\
\hline$f(\mathrm{~mm} / \mathrm{rev})$ & 0.12 & 0.2 \\
$a_{p}(\mathrm{~mm})$ & 0.2 & 0.2 \\
$V_{c}(\mathrm{~m} / \mathrm{min})$ & 200 & 200 \\
$R_{\varepsilon}(\mathrm{mm})$ & 0.8 & 0.4 \\
\hline
\end{tabular}

consists of the complex Fourier components of the profile with respect to period length. This spectrum is finally transformed into the space domain by means of an inverse Fourier transformation. The simulated and experimental profiles for both cutting conditions (a) and (b) are plotted in Figs. 10 and 11. For both cutting conditions, the experimental and simulated profiles correlate well. 


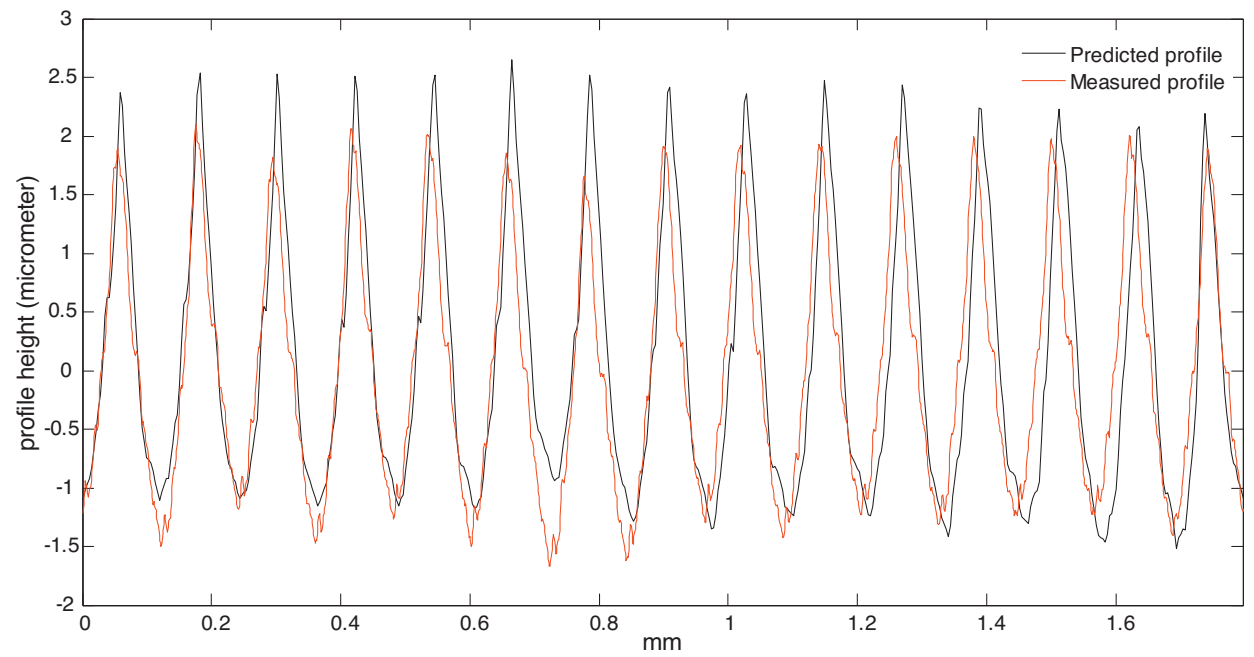

Fig. 10. Simulated and experimental profiles for cutting conditions (a) (cf. Table 2). $f=0.12 \mathrm{~mm}, a_{p}=0.2 \mathrm{~mm}, V_{c}=200 \mathrm{~m} / \mathrm{min}, R_{\varepsilon}=0.8 \mathrm{~mm}$.

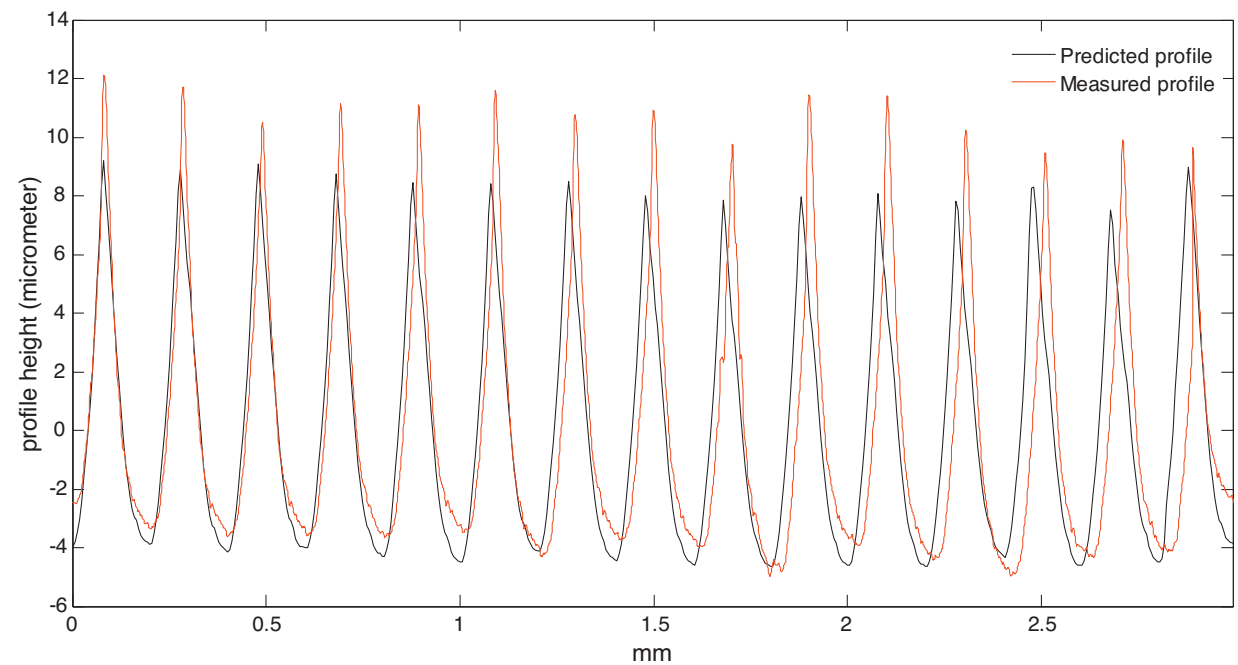

Fig. 11. Simulated and experimental profiles for cutting conditions (b) (cf. Table 2). $f=0.2 \mathrm{~mm}, a_{p}=0.2 \mathrm{~mm}, V_{c}=200 \mathrm{~m} / \mathrm{min}, R_{\varepsilon}=0.4 \mathrm{~mm}$.

\section{Conclusions}

This article presents a mathematical approach to surface profile prediction. The modeling process uses FFT operations applied to profiles, and is based on experimental design theory. Using a few preliminary cutting operations in various conditions, machined surfaces are measured and the effects of feed rate, depth of cut, cutting speed and insert nose radius are identified for the machining conditions of the study. First, the cutting parameters can be ranked in the following descending order according to their contribution to the surface profile amplitude: feed rate, and insert nose radius have the main effects on amplitude; depth of cut and cutting speed contribute to a far lesser extent. Second, the spectrum of the expected profile is expressed as a sum of the parameter effects spectra and one interaction spectrum. An inverse Fourier transform is applied to the obtained spectrum: this generates the expected surface profile. Two combinations of new cutting conditions are tested: simulations and experimental measurements compare well as regards shape, period and amplitude.

At this stage of the study, it is difficult to evaluate how the result regarding the parameters importance as well as the surface prediction would remain in a general case. It is clear that the effects of the cutting parameters were calculated for a given setup.
Consequently, the prediction of the profile is valid only in the used setup and the range of the investigated cutting parameters. The objective of the study was to develop a new methodology for a given setup. The extension of the proposed model to general cases of tool and machining conditions will be investigated in a future work.

\section{Acknowledgement}

The author is grateful to Nicolas Bost for his help in samples preparation and machining as well as profiles analyses.

\section{References}

Arizmendi, M., Campa, F.J., Fernández, J., López de Lacalle, L.N., Gil, A., Bilbao, E. Veiga, F., Lamikiz, A., 2009. Model for surface topography prediction in peripheral milling considering tool vibration. CIRP Annals - Manufacturing Technology 58 (1), 93-96.

Asilturk, I., Çunkaş, M., 2011. Modeling and prediction of surface roughness in turning operations using artificial neural network and multiple regression method. Expert Systems with Applications 38 (5), 5826-5832.

Benardos, P.G., Vosniakos, G.C., 2003. Predicting surface roughness in machining: a review. International Journal of Machine Tools and Manufacture 43 (8), 833-844.

Cakir, M.C., Ensarioglu, C., Demirayak, I., 2009. Mathematical modeling of surface roughness for evaluating the effects of cutting parameters and coating material. Journal of Materials Processing Technology 209 (1/1), 102-109. 
Costes, J.P., Moreau, V., 2011. Surface roughness prediction in milling based on tool displacements. Journal of Manufacturing Processes 13 (2), 133-140.

El-Sonbaty, I.A., Khashaba, U.A., Selmy, A.I., Ali, A.I., 2008. Prediction of surface roughness profiles for milled surfaces using an artificial neural network and fractal geometry approach. Journal of Materials Processing Technology 200 (1-3), $271-278$.

Grzesik, W., 1996. A revised model for predicting surface roughness in turning. Wear 194 (1-2), 143-148.

Grzesik, W., Brol, S., 2009. Wavelet and fractal approach to surface roughness characterization after finish turning of different workpiece materials. Journal of Materials Processing Technology 209 (5), 2522-2531.

Josso, B., Burton, D.R., Lalor, M.J., 2001. Wavelet strategy for surface roughness analysis and characterisation. Computer Methods in Applied Mechanics and Engineering 191 (8-10), 829-842.

Karayel, D., 2009. Prediction and control of surface roughness in CNC lathe using artificial neural network. Journal of Materials Processing Technology 209 (7), 3125-3137.
Lin, S.C., Chang, M.F., 1998. A study on the effects of vibrations on the surface finish using a surface topography simulation model for turning. International Journal of Machine Tools and Manufacture 38 (7), 763-782.

Lu, C., Costes, J.P., 2008. Surface profile prediction and analysis applied to turning process. International Journal of Machining and Machinability of Materials 4 (2/3), 158-180.

Quinsat, Y., Sabourin, L., Lartigue, C., 2008. Surface topography in ball end milling process: description of a 3D surface roughness parameter. Journal of Materials Processing Technology 195 (1-3), 135-143.

Selvam, M.S., Balakrishnan, K., 1977. The study of machined surface roughness by random analysis. Wear 41 (2), 287-293.

Wang, M., Chang, H., 2004. Experimental study of surface roughness in slot end milling AL2014-T6. International Journal of Machine Tools and Manufacture 44 (1), 51-57.

Wu, J., 2000. Simulation of rough surfaces with FFT. Tribology International 33 (1), 47-58. 